\title{
QUANTIFICAÇÃO DO METABOLISMO AERÓBIO E ANAERÓBIO DE LEVEDURA ALCOÓLICA SOB DIFERENTES CONDIÇÕES AMBIENTAIS
}

\author{
WALDEMAR GASTONI VENTURINI FILHO ${ }^{1}$ \\ RICARDO FIGUEIRA ${ }^{2}$ \\ MARIA MÁRCIA PEREIRA SARTORI ${ }^{3}$ \\ SOPHIA AUER ${ }^{4}$ \\ THALIA LEE LOPES DE ANDRADE ${ }^{5}$
}

\begin{abstract}
O objetivo do presente trabalho foi quantificar o metabolismo aeróbio (respiração) e anaeróbio (fermentação alcoólica) de levedura submetida a diferentes condições ambientais e de concentração celular. Para este estudo que foi desenvolvido em escala de bancada foram usados mostos ( $\left.15^{\circ} \mathrm{Brix}\right)$ produzidos a partir de caldo de cana e levedura seca de panificação da espécie Saccharomyces cerevisiae, mantidas em cultivo submerso. As condições ambientais e de concentração celular estudadas foram: a) aerobiose vs. anaerobiose; b) quantidade de inóculo (100, 200 e 300 g. $\left.\mathrm{L}^{-1}\right)$; c) enriquecimento do mosto com sulfato de amônio $\left(0,00 ; 0,01\right.$ e 0,02 mol. $\left.^{-1}\right)$; d) mosto com diferentes $\mathrm{pH}$ iniciais $(4,5$ e 6). As comparações estatísticas foram feitas mediante análise de variância, sendo as médias comparadas pelo Teste $t$ (ensaio com dois tratamentos) e Teste de Tukey (ensaios com três tratamentos). A levedura alcoólica utilizada neste trabalho apresentou metabolismo respirofermentativo, podendo ser classificada como anaeróbica facultativa do tipo fermentativo. O metabolismo respirofermentativo da levedura foi alterado pela concentração celular, $\mathrm{pH}$, enriquecimento com sulfato de amônio e condições de aerobiose e anaerobiose do mosto. Pela sua simplicidade, os ensaios descritos neste trabalho podem ser aproveitados para finalidades didáticas.
\end{abstract}

PALAVRAS-CHAVE: RESPIRAÇÃO, FERMENTAÇÃO, CATABOLISMO.

1 Doutor, Faculdade de Ciências Agronômicas, UNESP, Botucatu SP, Brasil (e-mail: venturini@fca.unesp.br); 2 Doutor, Faculdade de Ciências Agronômicas, UNESP, Botucatu SP, Brasil (e-mail: ricardofigueira@hotmail.com); 3 Doutor, Faculdade de Ciências Agronômicas, UNESP, Botucatu SP, Brasil (e-mail: mmpsartori@fca.unesp.br);

4 Bacharel em Engenharia de Alimentos, Universidade Técnica de Munique, Munique BY, Alemanha (e-mail: sophiaauer@gmx.de);

5 Estudante do curso de Engenharia Agronômica, Faculdade de Ciências Agronômicas, UNESP, Botucatu SP, Brasil (e-mail: thalialda@hotmail.com); 


\section{INTRODUÇÃO}

A levedura alcoólica, Saccharomyces cerevisiae, é um fungo unicelular, heterotrófico e quimiorganotrófico. Esta levedura é anaeróbia facultativa, isto é, cresce tanto em meios aeróbios como em anaeróbios. Apresenta metabolismo respiratório e/ou fermentativo em aerobiose e fermentativo em anaerobiose (RIBÉREAU-GAYON et al., 2006).

Para Käppeli (1986) e Gancedo e Serrano (1989), a respiração ocorre de forma simultânea com a fermentação em leveduras alcoólicas, num processo definido por esses autores como "respirofermentativo".

Segundo Castrillo e Ugalde (1994), com base nos diferentes modelos metabólicos apresentados por diferentes espécies de leveduras, elas podem ser classificadas como: a) aeróbias obrigatórias (Thricosporon e Rhodotorula) que apresentam apenas o metabolismo oxidativo, sendo incapazes de crescer na ausência de oxigênio; b) anaeróbias facultativas, que podem metabolizar a glicose de forma oxirredutora. Este grupo pode ser subdividido em dois subgrupos: 1) leveduras respiratórias (Candida e Kluyveromyces) em que mais de $70 \%$ da glicose é respirada aerobiamente; 2) leveduras fermentativas (Saccharomyces) em que mais de $90 \%$ do açúcar é catabolizado por via fermentativa.

Kocková-Kratochvílová (1990) afirmou que as leveduras, de acordo com sua atividade respiratória, podem ser divididas em três grupos: a) prevalência do metabolismo aeróbio (leveduras forrageiras), a respiração é responsável por $100 \%$ do catabolismo; b) os processos aeróbio e anaeróbio são semelhantes (leveduras patogênicas, de panificação, cervejeiras de alta fermentação), a respiração é responsável por 40 a $50 \%$ do catabolismo; c) o metabolismo anaeróbio prevalece (leveduras de destilaria, vinho e cervejeira de baixa fermentação), a respiração é responsável por 10 a $15 \%$ do catabolismo.

Briggs et al. (2004) classificaram as leveduras pelo modo como elas catabolizam os açúcares. As aeróbias obrigatórias utilizam exclusivamente a via respiratória e são incapazes de fermentarem açúcares (Rhodotorula, Lipomyces, Cryptococcus, Rhodosporidium e Saccharomycopsis). As anaeróbias facultativas metabolizam açúcares tanto pela via respiratória quanto pela via fermentativa. Este grupo é subdividido em dois subgrupos: a) leveduras respiratórias: são predominantes e catabolizam mais de $70 \%$ dos açúcares pela respiração (Candida, Hansenula, Kluyveromyces e Pichia); b) leveduras fermentativas: são caracterizadas pelas altas taxas de metabolismo de açúcar dos quais apenas $10 \%$ ou menos são catabolizados pela respiração (Saccharomyces, Brettanomyces e Schizosaccharomyces).

Boulton e Quain (2001) citados por Briggs et al. (2004) identificaram cinco mecanismos de regulação do catabolismo de açúcares pelas leveduras: a) Efeito Crabtree "short-term", redução da taxa de respiração pela adição de glicose ao meio; b) Efeito Crabtree "long-term", repressão ou inativação das enzimas respiratórias da levedura pela presença de glicose no meio; c) Efeito Pasteur, redução da taxa de glicólise sob condições aeróbias; d) Efeito Kluyver, utilização aeróbia obrigatória de dissacarídeos; e) Efeito Custer, estimulação aeróbia da taxa de fermentação da glicose.

Para Russel (2006), o oxigênio molecular tem uma função multifacetada na fisiologia da levedura cervejeira. Para ele, a fermentação do mosto cervejeiro é predominantemente anaeróbia, mas a levedura irá aproveitar o oxigênio do mosto no início do processo fermentativo. Segundo este autor, as leveduras necessitam de oxigênio molecular para sintetizar esteróis e ácidos graxos insaturados que estão presentes em quantidades sub ótimas no mosto. Se esses compostos forem adicionados ao mosto, a necessidade de oxigênio desaparece.

Gilliland (1981) afirmou que a presença de oxigênio no mosto cervejeiro é essencial para a boa reprodução da levedura e para uma rápida fermentação. Este autor, citando Kirsop (1974), atesta que a deficiência de oxigênio no mosto reduz a multiplicação das leveduras, a velocidade da fermentação, a formação de piruvato, álcool fúsel e acetoína, a absorção de nitrogênio e a viabilidade celular, e aumenta o $\mathrm{pH}$ e a formação de ésteres.

Ribéreau-Gayon et al. (2006) afirmou que para baixas concentrações de glicose no meio de cultura, as leveduras metabolizam os açúcares por meio da respiração ou fermentação. A aeração 
induz um aumento na produção de biomassa e uma diminuição na produção de etanol e no consumo de açúcar. Segundo esses autores, em mosto de uva, que contém elevadas concentrações de glucose, a levedura Saccharomyces cerevisiae apenas metaboliza açúcares pela via fermentativa. Mesmo na presença de oxigênio, a respiração é impossível. A repressão catabólica exercida pela glicose nas leveduras do vinho é muito forte. Neste caso, a aeração do mosto é importante para a síntese de esteróis e ácidos graxos insaturados, mas não para a respiração.

Ingledew (2009) escreveu que a concentração de açúcar no mosto de destilarias americanas de etanol é alta o suficiente (muito mais que $0,1 \% \mathrm{~m} / \mathrm{v}$ ), fazendo com que a levedura não seja capaz de crescer em condições verdadeiramente aeróbias, apesar da presença de $4 \mathrm{mg} \cdot \mathrm{L}^{-1}$ de oxigênio que satura o mosto a partir do espaço de ar no topo de fermentador. A levedura metaboliza a glicose de forma anaeróbica, gerando etanol e gás carbônico. De acordo com este autor, as células de levedura usam o oxigênio presente no mosto no início do processo fermentativo para sintetizar esteróis e ácidos graxos insaturados, indispensáveis na síntese de membrana celular, durante o seu crescimento. De acordo com este autor, as leveduras metabolizam mais de $90 \%$ do açúcar do mosto de forma anaeróbica. Para este autor, menos de $10 \%$ do açúcar é usado no anabolismo, isto é, na produção de biomoléculas responsáveis pelo crescimento celular.

Para Kocková-Kratochvílová (1990), o tipo de metabolismo depende não apenas da cepa de levedura (fator genético), mas também das condições ambientais. De acordo com ela, em pH alcalino a taxa de respiração aumenta, enquanto que em $\mathrm{pH}$ ácido a fermentação se torna mais vigorosa. A autora também afirma que a intensidade de respiração é diretamente proporcional à concentração celular, dentro de certos limites. Em concentrações celulares mais elevadas, a intensidade do processo respiratório decresce em favor do processo fermentativo.

Ainda de acordo com Kocková-Kratochvílová (1990), algumas substâncias inibem o processo respiratório, outras o estimulam, e ainda outras podem estimular ou inibir a fermentação. A pesquisadora afirma que sob condição de aerobiose, quando a levedura está oxidando açúcares, a adição de 0,01 mol.L-1 de sulfato de amônio aumenta a respiração em 200 \% no intervalo de 5 minutos.

Os objetivos do presente trabalho de pesquisa foram analisar os efeitos da concentração celular, do pH, do enriquecimento do mosto com sulfato de amônio, e da aerobiose e anaerobiose no metabolismo respiratório e fermentativo de levedura alcoólica. Um objetivo subjacente foi avaliar a possibilidade de utilizar os ensaios realizados no presente trabalho para finalidades didáticas.

\section{MATERIAL E MÉTODOS}

\subsection{DESCRIÇÃO DA METODOLOGIA}

A pesquisa foi dividida em quatro testes experimentais:

1 Aerobiose vs. anaerobiose: o mosto $(500 \mathrm{~mL})$ foi inoculado com fermento seco de panificação $(50 \mathrm{~g})$ e colocado para fermentar sob anaerobiose em garrafão de vidro (2,5 L), fechado com válvula air-lock. Na condição de aerobiose, o mosto foi fermentado em béquer de $2 \mathrm{~L}$ nas mesmas quantidades do teste em anaerobiose;

2 Concentração celular: o mosto $(1,0 \mathrm{~L})$ foi inoculado com fermento seco de panificação na proporção de 100, 200 e 300 g.L-1;

3 Enriquecimento com sulfato de amônio: o mosto $(1,0 \mathrm{~L})$ foi enriquecido com sulfato de amônio na concentração de 0,01 e 0,02 mol.L-1 e depois inoculado com $100 \mathrm{~g}$ de fermento seco de panificação. No tratamento testemunha não houve enriquecimento;

$4 \mathrm{pH}$ : o mosto $(1,0 \mathrm{~L})$ teve seu pH ajustado para 4,0, 5,0 e 6,0, adicionando soluções de ácido acético $\left(0,1 \mathrm{~mol} . \mathrm{L}^{-1}\right)$ ou hidróxido de sódio $\left(0,1 \mathrm{~mol} . \mathrm{L}^{-1}\right)$ e depois foi inoculado com fermento seco de panificação (100 g). Não houve correção de pH durante o processo fermentativo. 
Todos os testes foram conduzidos com 3 repetições em temperatura ambiente. Os mostos foram preparados a partir de caldo de cana ( $\left.20^{\circ} \mathrm{Brix}\right)$, sendo seu teor de sólidos solúveis corrigidos para $15^{\circ}$ Brix, por meio de diluição com água da rede pública duplamente filtrada em filtro de celulose (partícula) e carvão ativo (remoção do cloro).

Exceção feita ao teste de aerobiose vs. anaerobiose, em todos os demais preparou-se 1,0 litro de mosto e inoculou-se fermento seco de panificação (marca Fleischmann) da espécie Saccharomyces cerevisiae na proporção de $100 \mathrm{~g} \cdot \mathrm{L}^{-1}$. Usou-se béquer de 4 litros como fermentador e bastão plástico de agitação (parte constituinte do sistema de fermentação) para desfazer a espuma formada nas primeiras horas de fermentação.

Para estimar a massa de gás carbônico produzida no processo, todo o sistema de fermentação foi pesado a cada hora em balança de precisão (marca Gehaka, modelo BG2000). No experimento feito sob condições de aerobiose e anaerobiose, a balança utilizada foi da marca Filizola, modelo MF-6. Após a $8^{a}$ leitura, com a massa do mosto estabilizada, o experimento foi encerrado. As massas de gás carbônico produzidas durante o processo foram determinada pela diferença entre duas leituras consecutivas das massas de mosto em fermentação. A massa total de gás carbônico foi calculada pela diferença entre a massa inicial do mosto e a massa final do mosto fermentado (vinho).

O teor alcoólico do vinho foi obtido pelo método de destilação. Para essa determinação, utilizou-se um destilador de bancada (marca Buchi, modelo K355) e um densímetro digital (marca Mettler, modelo DA310). O teor alcoólico do vinho foi obtido mediante uso da tabela "Porcentagem de álcool em volume a $20{ }^{\circ} \mathrm{C} \mathrm{( \%} \mathrm{v/v)} \mathrm{correspondente} \mathrm{à} \mathrm{densidade} \mathrm{relativa"}$ (BRASIL, 2005).

\subsection{QUANTIFICAÇÃO DO METABOLISMO AERÓBIO E ANAERÓBIO}

A quantificação do metabolismo aeróbio e anaeróbio da levedura durante o processo fermentativo foi realizada estequiometricamente por meio de cálculo da sacarose respirada e fermentada, conforme as equações 1, 2, 3 e 4 .

A sacarose foi usada como açúcar de referência, pois representa $90 \%$ dos açúcares da cana, sendo que glicose e frutose são responsáveis pelos $10 \%$ restantes (LIMA, 2010). O teor de sacarose aparente foi determinado no caldo e no mosto pela análise de Pol (CTC, 2001), utilizando polarímetro (Anton Paar, modelo MCP 200).

O protocolo de cálculos mostrados a seguir está baseado nos estudos de Venturini Filho et al. (2013) e Venturini Filho et al. (2014).

Respiração:

$$
\begin{aligned}
& \underset{342}{\mathrm{C}_{12} \mathrm{H}_{22} \mathrm{O}_{11}}+\underset{18}{\mathrm{H}_{2} \mathrm{O}} \rightarrow \underset{180}{\mathrm{C}_{6} \mathrm{H}_{12} \mathrm{O}_{6}}+\underset{180}{\mathrm{C}_{6} \mathrm{H}_{12} \mathrm{O}_{6}} \\
& \underset{360}{2 \mathrm{C}_{6} \mathrm{H}_{12} \mathrm{O}_{6}}+\underset{384}{12 \mathrm{O}_{2}} \rightarrow \underset{528}{12 \mathrm{CO}_{2}}+\underset{216}{12 \mathrm{H}_{2} \mathrm{O}}
\end{aligned}
$$

Fermentação alcoólica:

$$
\begin{aligned}
& \mathrm{C}_{12} \mathrm{H}_{22} \mathrm{O}_{11}+\mathrm{H}_{2} \mathrm{O} \rightarrow \mathrm{C}_{6} \mathrm{H}_{12} \mathrm{O}_{6}+\mathrm{C}_{6} \mathrm{H}_{12} \mathrm{O}_{6} \\
& \begin{array}{llll}
342 & 18 & 180 & 180
\end{array}
\end{aligned}
$$

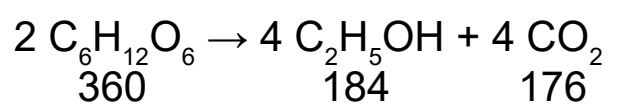




\subsubsection{Cálculo da sacarose fermentada (metabolismo anaeróbio)}

1 Determinou-se o teor alcoólico do mosto fermentado;

2 Calculou-se a massa de etanol proveniente da fermentação alcoólica (metabolismo anaeróbio);

3 A partir da massa de etanol, calculou-se estequiometricamente (Equações 3 e 4) a massa de sacarose fermentada.

\subsubsection{Cálculo da sacarose respirada (metabolismo aeróbio)}

1 Mensurou-se a massa total de $\mathrm{CO}_{2}$ produzido no processo, proveniente tanto do metabolismo aeróbio como do anaeróbio (massa inicial menos massa final do sistema de fermentação);

2 Converteu-se estequiometricamente a massa de etanol em massa de gás carbônico (Equações 3 e 4) formado no metabolismo anaeróbio;

3 Calculou-se a massa de $\mathrm{CO}_{2}$ proveniente da respiração, mediante subtração da massa total de gás carbônico gerado no processo pela massa de gás carbônico produzido pelo metabolismo anaeróbio;

4 Converteu-se estequiometricamente a massa de $\mathrm{CO}_{2}$ proveniente do metabolismo respiratório em massa de sacarose respirada (Equações 1 e 2);

5 Obteve-se a massa total de sacarose catabolizada pela soma da massa de sacarose fermentada e sacarose respirada.

6 Efetuou-se a quantificação relativa de sacarose fermentada e respirada por meio das equações 5 e 6 :

$$
\begin{aligned}
& \text { Sacarose fermentada }(\%)=\frac{M S F}{M S F+M S R} \\
& \text { Sacarose respirada }(\%)=\frac{M S R}{M S R+M S F}
\end{aligned}
$$

As abreviações usadas nas equações 5 e 6 significam: MSF = massa de sacarose fermentada; $M S R$ = massa de sacarose respirada.

A análise estatística dos resultados foi realizada por meio de Análise de Variância (VIEIRA, 2006), sendo as médias comparadas pelo Teste de Tukey ( $\alpha=5 \%$ ). Para o ensaio aerobiose vs. anaerobiose, as médias foram comparadas pelo Teste t. Os cálculos estatísticos foram efetuados com auxílio do programa Minitab 16 Statistical Sofware (2010).

\section{RESULTADOS E DISCUSSÃO}

A quantificação do metabolismo aeróbio (respiração) e anaeróbio (fermentação alcoólica) realizada neste trabalho deve ser considerada uma estimativa pelo fato de que nem toda sacarose metabolizada ter sido respirada e/ou fermentada. Uma pequena parte do açúcar é usada em outros tipos de metabolismos. Ingledew (2009) considera que menos de $10 \%$ da glicose dos mostos (de destilarias americanas de bioetanol) são anabolizados pelas leveduras alcoólicas, visando a multiplicação celular.

Apesar dos resultados apresentados neste trabalho serem considerados estimativas, eles avaliam o comportamento metabólico das leveduras em diferentes condições de meio e população. O método estequiométrico utilizado nos cálculos é confiável, como já demonstrado em trabalhos anteriores (VENTURINI FILHO et al., 2013; VENTURINI FILHO et al., 2014). 


\subsection{ENSAIO AEROBIOSE VS. ANAEROBIOSE}

Sob condição de aerobiose (fermentador aberto), a levedura metabolizou uma quantidade maior de sacarose $(71,1 \mathrm{~g})$ quando se compara à condição de anaerobiose (fermentador fechado com válvula air lock) em que o fermento consumiu $62,1 \mathrm{~g}$ do açúcar. A maior quantidade de sacarose metabolizada sob aerobiose está associada ao processo respiratório da levedura. Observa-se que sob aerobiose a levedura produziu menos etanol, evidenciando o desvio do metabolismo fermentativo para o respiratório, o que caracteriza o Efeito Pasteur. Kocková-Kratochvílová (1990) afirmou que as leveduras de cerveja se parecem com a maioria das leveduras de vinho, para as quais o oxigênio reprime levemente a fermentação alcoólica. Foi o que se observou no presente estudo com a levedura de panificação fermentando mosto de cana de açúcar (Tabela 1).

Quando o mosto de caldo de cana foi metabolizado pela levedura sob aerobiose, a taxa de respiração foi de $23,7 \%$, enquanto que em anaerobiose esta taxa foi de apenas 1,6\%. Ou seja, sob anaerobiose, a levedura respirou o oxigênio que estava inicialmente dissolvido no mosto; mas quando esta fonte de oxigênio foi esgotada, ela passou a fermentar a sacarose por meio da fermentação alcoólica. Pelo fato do fermentador estar fechado, o oxigênio atmosférico não pode se difundir pelo mosto em fermentação, privando a levedura deste gás (Tabela 1).

Embora os resultados mostrados na Tabela 1 possam sugerir que para a produção de etanol é preferível manter a levedura sob condição de anaerobiose por meio do uso de fermentadores fechados, o que acontece na prática industrial, deve-se ter em conta que a levedura alcoólica necessita de oxigênio não só para respirar - e consequentemente se multiplicar e se revigorar mas também para a produção de esteróis e ácidos graxos, componentes das membranas celulares (GILLILAND, 1981; RUSSEL, 2006). Por isso, o oxigênio deve ser visto como um elemento indispensável para a célula de levedura alcoólica.

\section{TABELA 1. QUANTIFICAÇÃO DA SACAROSE RESPIRADA E FERMENTADA POR LEVEDURA ALCOÓLICA EM MOSTO DE CALDO DE CANA MANTIDO EM CONDIÇÕES DE AEROBIOSE E ANAEROBIOSE.}

\begin{tabular}{lcc}
\hline & Aerobiose & Anaerobiose \\
\hline Teor alcoólico $(\% \mathrm{v} / \mathrm{v})^{*}$ & $7,4 \mathrm{~b}$ & $8,3 \mathrm{a}$ \\
Volume de etanol $(\mathrm{mL})$ & 37,0 & 41,6 \\
Massa de etanol $(\mathrm{g})$ & 29,2 & 32,9 \\
Massa de $\mathrm{CO}_{2}$ da fermentação $(\mathrm{g})$ & 27,9 & 31,4 \\
Massa de sacarose fermentada $(\mathrm{g})$ & 54,3 & 61,1 \\
Massa de $\mathrm{CO}_{2}$ da fermentação e respiração $(\mathrm{g})$ & 54,0 & 33,0 \\
Massa de $\mathrm{CO}_{2}$ da respiração $(\mathrm{g})$ & 26,1 & 1,6 \\
Massa de sacarose respirada $(\mathrm{g})$ & 16,9 & 1,0 \\
Massa de sacarose fermentada e respirada $(\mathrm{g})^{*}$ & $71,1 \mathrm{a}$ & $62,1 \mathrm{~b}$ \\
Sacarose fermentada $(\%)^{*}$ & $76,3 \mathrm{~b}$ & $98,4 \mathrm{a}$ \\
Sacarose respirada $(\%)^{*}$ & $23,7 \mathrm{a}$ & $1,6 \mathrm{~b}$ \\
\hline
\end{tabular}

*Análise de Variância e médias comparadas pelo Teste $t(\alpha=5 \%)$. 


\subsection{ENSAIO CONCENTRAÇÃO CELULAR}

De acordo com os dados da tabela 2, o metabolismo foi mais intenso no tratamento 200 g.L-1 (145,5 g de sacarose fermentada e respirada).

A taxa de respiração foi proporcional à quantidade de levedura inoculada. Esses dados sugerem que em concentrações mais baixas de inóculo, a levedura assimila o açúcar pelo processo respirofermentativo, sendo que o gás carbônico produzido a partir deste metabolismo arrasta consigo o oxigênio dissolvido no mosto. Em concentrações mais elevadas de levedura, as células devem assimilar prontamente o oxigênio do meio, metabolizando-o pelo mesmo processo respirofermentativo, esgotando-o antes do seu arraste pelo $\mathrm{CO}_{2}$ produzido. Kocková-Kratochvílová (1990) afirmou que a intensidade de respiração é diretamente proporcional à concentração celular, quando se trabalha na faixa de $2-60$ * $10^{6}$ células. $\mathrm{mL}^{-1}$.

\section{TABELA 2. QUANTIFICAÇÃO DA SACAROSE RESPIRADA E FERMENTADA POR LEVEDURA ALCOÓLICA EM MOSTO DE CALDO DE CANA INOCULADO NA PROPORÇÃO DE 100, 200 E 300 G.L-1.}

\begin{tabular}{|c|c|c|c|}
\hline & \multicolumn{3}{|c|}{ Levedura $\left(g \cdot \mathrm{L}^{-1}\right)$} \\
\hline & 100 & 200 & 300 \\
\hline Teor alcoólico $(\% \mathrm{v} / \mathrm{v})^{*}$ & $7,7 \mathrm{a}$ & $7,6 \mathrm{a}$ & $6,2 \mathrm{~b}$ \\
\hline Volume de etanol $(\mathrm{mL})$ & 77,1 & 75,8 & 61,9 \\
\hline Massa de etanol $(\mathrm{g})$ & 60,9 & 59,9 & 48,9 \\
\hline Massa de $\mathrm{CO}_{2}$ da fermentação $(\mathrm{g})$ & 58,3 & 57,3 & 46,8 \\
\hline Massa de sacarose fermentada (g) & 113,2 & 111,3 & 90,9 \\
\hline Massa de $\mathrm{CO}_{2}$ da fermentação e respiração $(\mathrm{g})$ & 96,2 & 110,2 & 118,6 \\
\hline Massa de $\mathrm{CO}_{2}$ da respiração $(\mathrm{g})$ & 37,9 & 52,9 & 71,8 \\
\hline Massa de sacarose respirada $(\mathrm{g})$ & 24,5 & 34,3 & 46,5 \\
\hline Massa de sacarose fermentada e respirada $(\mathrm{g})^{\star}$ & $137,8 \mathrm{~b}$ & $145,5 \mathrm{a}$ & $137,5 \mathrm{~b}$ \\
\hline Sacarose fermentada $(\%)^{*}$ & $82,2 \mathrm{a}$ & $76,4 \mathrm{~b}$ & $66,1 \mathrm{c}$ \\
\hline Sacarose respirada $(\%)^{*}$ & $17,8 \mathrm{c}$ & $23,6 \mathrm{~b}$ & $33,9 a$ \\
\hline
\end{tabular}

\subsection{ENSAIO ENRIQUECIMENTO COM SULFATO DE AMÔNIO}

Os dados da Tabela 3 evidenciam que a levedura alcoólica metabolizou uma maior quantidade de açúcar nos mostos enriquecidos com sulfato de amônio (137,9 e 139,4 g). Também é possível observar que a maior quantidade de açúcar metabolizada nesses tratamentos foi direcionada preferencialmente para a fermentação alcoólica em detrimento do processo respiratório.

A maior taxa metabólica observada nos tratamentos que receberam adição de sulfato de amônio está de acordo com as observações de Ribéreau- Gayon et al. (2006) para quem o enriquecimento de mosto de uva com nitrogênio contribui para a completa assimilação de açúcares pelas leveduras alcoólicas, evitando fermentações lentas e incompletas. Observação semelhante foi feita por Ingledew (2009), para quem o enriquecimento de mosto (obtido a partir de milho) com 
fontes de nitrogênio (suplemento nutricional, extrato de levedura e ureia) acelera o crescimento celular e o processo fermentativo. Por outro lado, Lea e Drilleau (2003) explicaram que baixos níveis de nitrogênio no mosto de maçã limitam severamente o crescimento da levedura alcoólica durante a produção de sidra. De acordo com esses autores, mostos de maçã pobres em nitrogênio acarretam fermentações incompletas.

\section{TABELA 3. QUANTIFICAÇÃO DA SACAROSE RESPIRADA E FERMENTADA POR LEVEDURA ALCOÓLICA EM MOSTO DE CALDO DE CANA ENRIQUECIDO COM SULFATO DE AMÔNIO (0,00 MOL.L-1, 0,01 MOL.L-1 E 0,02 MOL.L-1).}

\begin{tabular}{|c|c|c|c|}
\hline & \multicolumn{3}{|c|}{ Sulfato de Amônio (mol. $\mathrm{L}^{-1}$ ) } \\
\hline & 0,00 & 0,01 & 0,02 \\
\hline Teor alcoólico $(\% \mathrm{v} / \mathrm{v})^{*}$ & $6,9 b$ & $7,8 \mathrm{a}$ & $8,0 \mathrm{a}$ \\
\hline Volume de etanol (mL) & 68,9 & 78,4 & 80,3 \\
\hline Massa de etanol (g) & 54,4 & 62,0 & 63,4 \\
\hline Massa de $\mathrm{CO}_{2}$ da fermentação $(\mathrm{g})$ & 52,1 & 59,3 & 60,7 \\
\hline Massa de sacarose fermentada (g) & 101,2 & 115,2 & 117,9 \\
\hline Massa de $\mathrm{CO}_{2}$ da fermentação e respiração $(\mathrm{g})$ & 92,5 & 94,4 & 93,9 \\
\hline Massa de $\mathrm{CO}_{2}$ da respiração $(\mathrm{g})$ & 40,4 & 35,1 & 33,2 \\
\hline Massa de sacarose respirada (g) & 26,2 & 22,8 & 21,5 \\
\hline Massa de sacarose fermentada e respirada $(\mathrm{g})^{*}$ & $127,4 \mathrm{~b}$ & 137,9 a & $139,4 \mathrm{a}$ \\
\hline Sacarose fermentada $(\%)^{\star}$ & 79,4 b & 83,5 a & 84,6 a \\
\hline Sacarose respirada $(\%)^{*}$ & 20,6 a & $16,5 b$ & $15,4 \mathrm{~b}$ \\
\hline
\end{tabular}

\subsection{ENSAIO COM DIFERENTES PH}

A maior quantidade de sacarose metabolizada pelo processo respirofermentativo ocorreu em pH 4 e 5. Esses resultados estão em concordância com as afirmações de que a levedura alcoólica desempenha melhor suas funções metabólicas em pH entre 4 e 5. Lima, Basso e Amorim (2001) relataram que a fermentação alcoólica (para produção de bioetanol) se desenvolve numa ampla faixa de $\mathrm{pH}$, sendo a mais adequada aquela situada entre 4 e 5.

No $\mathrm{pH} 4$, a levedura apresentou a menor taxa respiratória (16,7\%) (Tabela 4). Este resultado está de acordo com as informações de Kocková-Kratochvílová (1990). Segundo esta pesquisadora, a intensidade de respiração da levedura aumenta em meio alcalino, enquanto $\mathrm{pH}$ ácido favorece $\mathrm{o}$ processo fermentativo.

Os ensaios realizados neste trabalho são de fácil execução, não demandam equipamentos sofisticados, e os cálculos são relativamente simples. Por essas características, esses ensaios podem perfeitamente ser aproveitados para finalidades didáticas, principalmente em disciplinas de pós-graduação. 


\section{TABELA 4. QUANTIFICAÇÃO DA SACAROSE RESPIRADA E FERMENTADA POR LEVEDURA ALCOÓLICA EM MOSTO DE CALDO DE CANA COM PH 4, 5 E 6.}

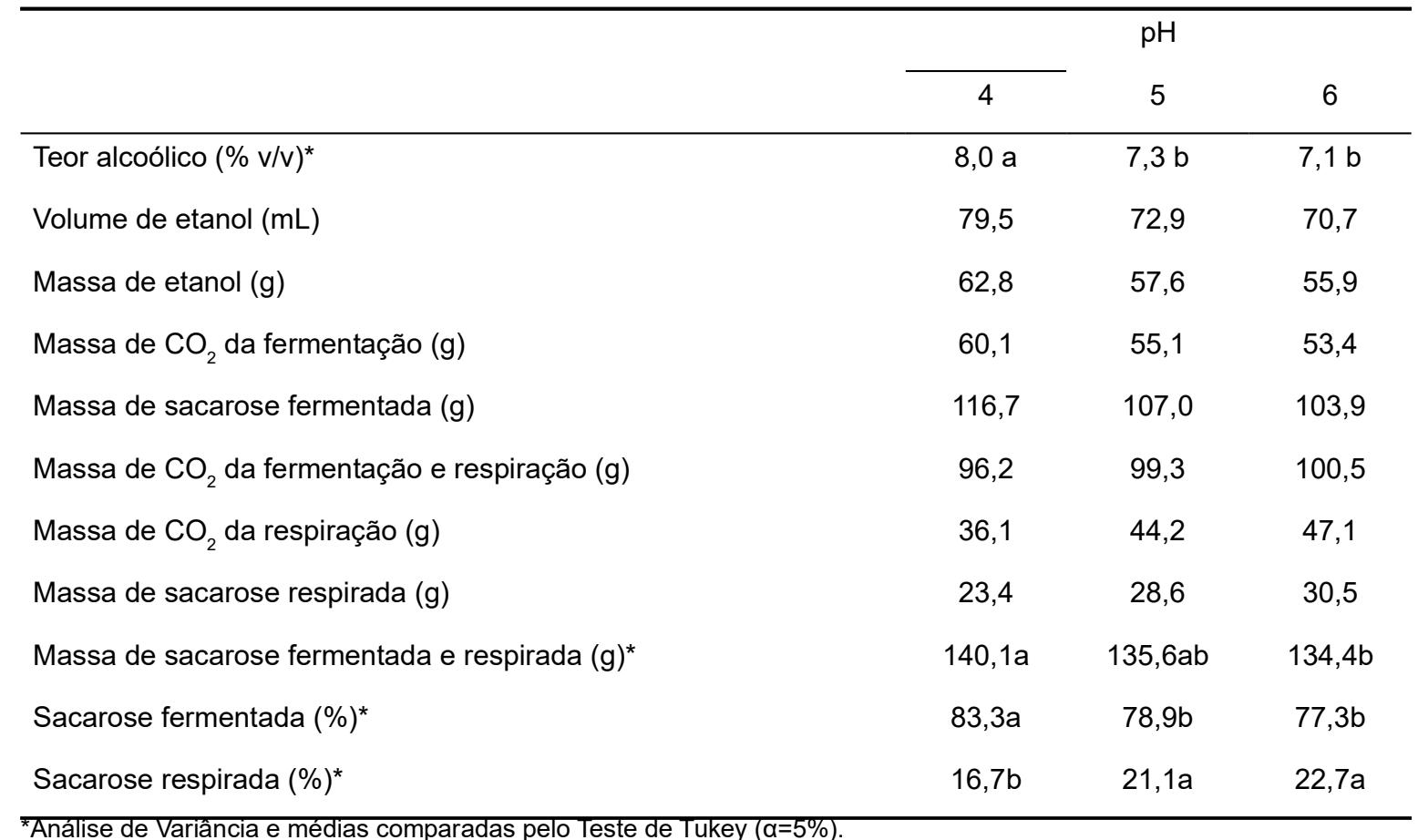

\section{CONCLUSÕES}

A levedura alcoólica utilizada neste trabalho apresentou metabolismo respirofermentativo, podendo ser classificada como anaeróbica facultativa, do tipo fermentativo. O metabolismo respiro fermentativo da levedura foi alterado pela concentração celular, $\mathrm{pH}$, enriquecimento com sulfato de amônio, e condições de aerobiose e anaerobiose do mosto. Os ensaios descritos neste trabalho, pela sua simplicidade, podem perfeitamente ser aproveitados para finalidades didáticas.

\section{ABSTRAT \\ QUANTIFICATION OF AEROPIAN AND ANAEROBIC METABOLISM OF ALCOHOLIC YEAST UNDER DIFFERENT ENVIRONMENTAL CONDITIONS}

The aim of this work was quantify the aerobic metabolism (respiration) and anaerobic metabolism (alcoholic fermentation) of yeast at different environmental conditions and different cellular concentration. For this study that was made in bench scale were used musts $\left(15^{\circ} \mathrm{Brix}\right)$ produced from cane juice and bread dry yeast Saccharomyces cerevisiae maintained in submerged cultivation. The environmental conditions and cellular concentrations studied were: a) aerobiosis vs. anaerobiosis; b) quantity of inoculum (100, 200 and $300 \mathrm{g.L-1})$; c) must enriched with ammonium sulphate ( $0.00 ; 0.01$ and $0.02 \mathrm{M})$; d) must with different initial $\mathrm{pH}(4,5$ and 6$)$. Statistical analysis were made using variance analysis and the averages were compared by $\mathrm{t}$ Test (assay with two treatments) and Tukey test (assays with three treatments). The alcoholic yeast used in this work showed respirofermentative metabolism and it was classified as facultative anaerobic of the fermentative type. The yeast's respirofermentative metabolism was changed by the cellular concentrations, $\mathrm{pH}$, enrichment with ammonium sulfate and aerobic and anaerobic conditions of must. By its simplicity, the assays described in this work can be used for teaching purposes.

KEYWORDS: RESPIRATION, FERMENTATION, CATABOLISM. 


\section{REFERÊNCIAS}

1 BRASIL. Ministério da Saúde. Agência Nacional de Vigilância Sanitária. Métodos físico-químicos para análise de alimentos. 4 ed. Brasília: Ministério da Saúde, 2005. 1018p.

2 BRIGGS, D. E.; BOULTON, C. A.; BROOKES, P. A.; STEVENS, A. Metabolism of wort by yeast. Brewing: science and practice. Cambridge: Woodhead Publishing, 2004. cap. 12, p.401-468.

3 CASTRILLO, J. I.; UGALDE, U. O. A general model of yeast energy metabolism in aerobic chemostat culture. Yeast, Chichester, v. 10, p. 185-197, 1994.

4 CTC - Centro de Tecnologia Copersucar. Manual de controle químico da fabricação de açúcar. Piracicaba: Centro de Tecnologia Copersucar, 2001.

5 GANCEDO, C.; SERRANO, R. Energy-yielding metabolism. In: ROSE, A. H.; HARRISON, J. S. (ed.). The yeast. New York: Academic Press, 1989. v. 3, p. 205-259,

6 GILLILAND, R. B. Brewing yeast. In: POLLOCK, J. R. A. (Ed.). Brewing Science. London, Academic Press, 1981. v. 2, cap. 1, p. 1-60.

7 INGLEDEW, W. M. Yeast: physiology, nutrition and ethanol production. In: INGLEDEW, W. M.; KELSALL, D. R.; AUSTIN, G. D.; KLUHSPIES, C. The alcohol textbook. 5. ed. Nottingham: Nottingham University Press, 2009. cap. 9, p. 101-113.

8 KÄPPELI, O.; Regulation of carbon metabolism in Saccharomyces cerevisiae and related yeast. Advances in Microbial Physiology, Maryland Heights, v. 28, p. 181-208, 1986.

9 KOCKOVÁ-KRATOCHVÍLOVÁ, A. Yeast metabolism. Yeast and yeast-like organisms. Weinheim: VCH, 1990. cap. 5, p. 304-390.

10 LEAA. G. H.; DRILLEAU, J. F. Cidermaking. In: LEA, A. G. H.; PIGGOTT, J. R. Fermented beverage production. 2. ed. New York: Kluwer Academic /Plenum Publisher, 2003. cap. 4, p. 59-87.

11 LIMA, U. A. Cana-de-açúcar. In: LIMA, U. A. Matérias-primas dos alimentos. São Paulo: Blucher, 2010. cap. 5.2, p. 128-140.

12 LIMA, U. A.; BASSO, L. C.; AMORIM, H. V. Produção de etanol. In: LIMA, U. A.; AQUARONE, E.; BORZANI, W.; SCHMIDELL, W. Biotecnologia industrial: processos fermentativos e enzimáticos. São Paulo: Edgard Blücher, 2001. cap. 1, p. 1-43.

13 MINITAB 16, Minitab Inc., State College, Pennsylvania, USA, 2010.

14 RIBÉREAU-GAYON, P.; DUBOURDIER, D.; DONĖCHE, B.; LONVAUD, A. Biochemistry of alcoholic fermentation and metabolic pathway of wine yeasts. Handbook of enology: the microbiology of wine and vinifications. Chichester: Wiley, 2006. cap. 2, p. 53-77.

15 RUSSELL, I. Yeast. In: PRIEST, F. G.; STEWART G. G. Handbook of brewing. Boca Raton: Taylor \& Francis, 2006. cap. 8 , p.281-332.

16 VENTURINI FILHO, W. G.; BRUNELLI, L. T.; TONIATO, J.; NOJIMOTO, T.; NOVAES, F. V. Método simples para quantificar o metabolismo aeróbio e anaeróbio de levedura alcoólica. Boletim do CEPPA, Curitiba, v. 31, n. 2, p. 227236, 2013.

17 VENTURINI FILHO, W. G.; BRUNELLI, L. T.; TONIATO, J.; NOJIMOTO, T. Quantificação do metabolismo aeróbio e anaeróbio de levedura alcoólica por método estequiométrico. Revista Energia na Agricultura, Botucatu, v. 29, n. 2, p. 135-141, 2014.

18 VIEIRA, S. Análise de variância (ANOVA). São Paulo: Atlas, 2006. 204 p. 